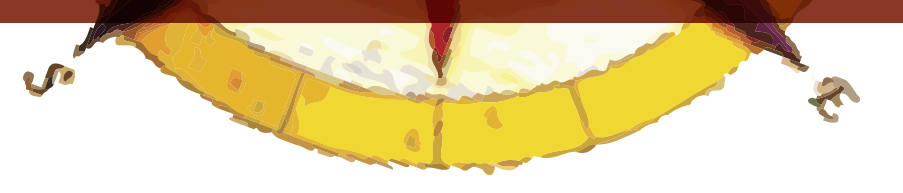

\title{
IMAGENS DA "EDUCAÇÃO INCLUSIVA": ALGUNS APONTAMENTOS ACERCA DO ESPAÇO E DO TEMPO ESCOLARES
}

\author{
Ana Paula Nunes Chaves ${ }^{1}$ \\ Leila Procópia do Nascimento ${ }^{2}$ \\ Sonia Maria Vanzella Castellar ${ }^{3}$
}

\section{RESUMO}

O objetivo deste texto é discutir o tempo e o espaço escolares, e como estes elementos estruturantes da cultura escolar se configuram com a temática da educação inclusiva, uma vez que acreditamos que a proposta de educação inclusiva gera na escola uma mudança significativa na estrutura de tempo e espaço estabelecida na medida em que considera o estudante como sujeito ativo do/no processo educativo, reconhecendo sua singularidade e as diferentes linguagens e ritmos de aprendizagem. Diante das inúmeras tentativas nas reformas políticas educacionais e nas articulações de pesquisadores interessados no "pensar" a escola, o currículo e a cultura escolar se mostra como um dos maiores desafios das políticas nacionais e internacionais.

Palavras Chave: Educação inclusiva, cultura escolar, espaço e tempo.

\section{RESUMEN}

El objetivo de este texto es discutir el tiempo y el espacio escolar, y cómo estos elementos estructurantes de la cultura escolar se configuran con la temática de la educación inclusiva, una vez que creemos que la propuesta de educación inclusiva genera en la escuela un cambio significativo en la estructura de tiempo y espacio establecida en la medida en que considera el estudiante como sujeto activo del/en el proceso educativo, reconociendo su singularidad y los diferentes lenguajes y ritmos de aprendizaje. Delante de las innumerables tentativas en las reformas políticas educacionales y en las articulaciones de investigadores interesados en el "pensar" la escuela, el currículo y la cultura escolar se muestra como uno de los mayores desafíos de las políticas nacionales e internacionales.

Palabras Clave: Educación inclusiva, cultura escolar, espacio y tiempo.

1 Doutoranda do Programa de Pós-graduação em Educação da Universidade de São Paulo - USP.

2 Doutoranda do Programa de Pós-graduação em Educação da Universidade Federal de Santa Catarina - UFSC.

3 Professora Doutora da Faculdade de Educação da Universidade de São Paulo - USP. 


\section{ABSTRACT}

The objective of this text is to discuss the time and school time, and how these structural elements relative to school culture are related with inclusive education themes, once we believe inclusive education proposal generates in the school significant changes in time and space structure, considering the student as an active subject in the educative process, recognizing his/her singular and different languages and learning rhythms. In a context of countless attempts in the educational politics reforms and the articulation of researchers interested in "thinking" the school, curriculum and school culture, it shows one of the biggest challenges in national and international politics.

Keywords: Inclusive education, school culture, space and time.

\section{INTRODUÇÃO}

Entre o final da década de 1980 e início dos anos 2000, os debates sobre escola, currículo e reformas educativas ganham terreno nas discussões de âmbito internacional. Essas temáticas foram se constituindo, enquanto necessárias, e sempre estiveram articuladas às transformações sociais, visto que a escola é produto de uma sociedade e está ligada a diferentes fins e interesses em cada momento histórico. No campo brasileiro, se acentuam as demandas de transformações na escola e alguns exemplos do que queremos chamar a atenção podem ser vislumbrados com a Lei de Diretrizes e Bases da Educação Nacional, com a proposta de Progressão Continuada, a escola com regime de tempo integral, as avaliações externas a que as escolas estão submetidas, a extensão do Ensino Fundamental para nove anos de duração, a proposta de educação inclusiva. Gallego e Silva (2012, p. 7) nutrem a reflexão quando apontam que "todos os exemplos mencionados são expressivos por alterarem ou criarem novos marcos temporais e ritmos no cotidiano escolar para gestores, professores e alunos como também para funcionários e famílias. Cada inclusão implica ressignificações e, de certo modo, (re) invenções das práticas cotidianas e sentidos atribuidos às escolas." Tais implementações com orientações legais e pedagógicas repercutiram em pesquisas e práticas até os dias de hoje, haja vista inúmeras tentativas nas reformas políticas educacionais e nas articulações de pesquisadores interessados no "pensar" a escola, o currículo e a cultura escolar .

Face a esse pano de fundo - no que diz respeito às inúmeras mudanças estabelecidas por leis e decretos na educação brasileira - em especial à democratização do ensino, nos últimos 30 anos o Brasil tem ensaiado um modelo de educação inclusiva a partir dos preceitos europeus. Entretanto, é válido apontar que os conceitos de inclusão escolar e educação inclusiva são distintos e há necessidade de um esclarecimento visto a confusão em termos conceituais que é feita em trabalhos que discorrem sobre o tema. De acordo com Bueno (2008, p. 49) "na medida em que inclusão escolar referese a uma proposição política em ação, de incorporação de alunos que tradicionalmente têm sido excluídos da escola, enquanto que educação inclusiva refere-se a um objetivo politico a ser alcançado".

A inclusão escolar, apesar de ser uma proposta já introduzida há algum tempo na pauta de interesse da educação básica do país, por meio de uma legislação que foi se adequando ao longo desses 30 anos e que atualmente garante o direito de acesso à educação regular a todas as crianças

4 O termo cultura escolar está atrelado a uma série de reflexões onde se utilizam com mais ênfase os trabalhos de Dominique Julia (2001), André Chervel (1998), Jean-Claude Forquin (1993) e António Viñao Frago (2006). Apesar das similitudes e diferenças nos quadros conceituais apresentados pelos autores, para esse trabalho procurouse basear-se nas reflexões em torno dos estudos de Viñao Frago (2001, 2006). 
(Brasil, 1988), somente na medida em que esses estudantes começaram a frequentar as escolas é que o assunto começou a ser tratado com mais interesse e também com maior urgência. Apesar de o contexto brasileiro apresentar um conjunto de leis que procura assegurar direitos a esses escolares, é com a Lei de Diretrizes e Bases da Educação Nacional (LDBEN) de 1996 que as escolas passaram a ser convocadas institucionalmente a adequar-se à educação inclusiva. A partir do momento que a escola universaliza o acesso a todas as pessoas, pessoas que até então eram excluídas da participação efetiva na vida escolar formal passam a ter também uma "oportunidade" de frequentar este ambiente.

Estes novos elementos no cenário educacional serviram, em muito, para quebrar paradigmas. Urgiram num contexto de rupturas, trazendo à tona novas demandas para a escola e para os profissionais. Como aceitar todos na escola? De que forma assegurar a inserção e permanência de estudantes que necessitam de adaptações curriculares, pedagógicas e estruturais em uma escola que historicamente foi pensada em uma lógica homogeneizadora e normalizadora? De que maneira a inclusão escolar cria novos marcos temporais e espaciais no dia-a-dia da instituição a ponto de se constituir como um imperativo de mudança?

A problemática consiste no entendimento da gênese da escola como espaço não democrático de articulação dos direitos humanos. É fato que a instituição escolar apresenta um histórico com caráter excludente e seletivo, e nesse sentido, não foi e não tem sido algo simples e fácil articular a lei com a realidade concreta estabelecida em seu interior.

De acordo com De Paula (2009), a escola originou, ao longo de sua existência, uma cultura específica que se organizou em práticas e hábitos, muitas vezes, de natureza burocrática e conservadora, e diante da possibilidade de todos os cidadãos brasileiros terem direito à educação, a escola é levada à necessidade de se reestruturar. Esse modelo de escola burocrática e conservadora que conhecemos não atende às demandas suscitadas pela inclusão, pois a educação inclusiva conduz a uma nova forma de pensar e agir a cultura escolar.

Este repensar a educação escolar implica necessariamente em uma nova forma de compreender a escola via cultura escolar, ou seja, compreender as diferentes manifestações das práticas instauradas no interior das escolas, transitando de alunos a professores, de normas a teorias (Viñao Frago, 1995 citado por Faria Filho et al, 2004). Compreender o que representa esse conjunto de normas e práticas educativas que reflete tudo o que acontece no interior da escola pode, sobretudo, colocar em cena estratégias e possibilidades para uma real escola inclusiva.

Para Viñao Frago (1995, p. 69), a cultura escolar é toda a vida escolar,

hechos e ideas, mentes y cuerpos, objetos y conductas, modos de pensar, decir y hacer. Lo que sucede es que en este conjunto hay algunos aspectos que son más relevantes que otros, en el sentido que son elementos organizadores que la conforman y definen. Dentre ellos elijo dos a lo que he dedicado alguna atención en los últimos años: el espacio y el tiempo escolares.

Amparados nos estudos de Viñao Frago, o espaço e o tempo escolares talvez sejam os exemplos mais concretos para o encaminhamento de nossa reflexão. Visto que a escola inclusiva não se configurou na sociedade brasileira como uma boa referência de respeito aos direitos humanos e respeito às diversidades. Ou seja, a cultura do uso do espaço e tempo escolares no momento em que a legislação possibilitou a abertura da escola para todos, criou também contradições entre a realidade 
concreta estruturada na escola e (im) possibilitou o acesso de estudantes ao convívio neste espaço.

Outros elementos, não menos importantes que os dois referidos - o espaço e o tempo escolares, também são citados pelo autor, como os discursos educativos e os processos de comunicação utilizados no ensino. Entretanto, para este texto, haverá especial destaque acerca do tempo e, principalmente, do espaço escolar, e como estes elementos estruturantes da cultura escolar se configuram com a temática da educação inclusiva.

\section{A ESCOLA... INCLUSIVA?}

A democracia "no sentido etimológico da palavra, significa o governo do povo, o governo da maioria [...] a comunidade política está assim aberta ao seu desenvolvimento e aperfeiçoamento graças às instituições que ganham o estatuto da imortalidade" (Rosenfield, 2007, p. 9). Nas palavras de Habermas (1997, p. 145), "o princípio da democracia destina-se a amarrar um procedimento de normatização legítima do direito. Ele significa, com efeito, que somente podem pretender validade legítima as leis jurídicas capazes de encontrar o assentimento de todos os parceiros do direito, num processo de normatização discursiva". Para Habermas (1997, p. 145), é necessário a institucionalização dos direitos fundamentais, como:

[...] direitos fundamentais à participação, em igualdade de chances, em processo de formação da opinião e da vontade nos quais os civis exercitam sua autonomia política e através dos quais eles criam direito legítimo. É necessário que a autonomia assuma uma figura concreta, utilizando-se para isso de um princípio de legislação concreto, usado factualmente pelos cidadãos. Este princípio que é decorrente da institucionalização jurídica do princípio do discurso é chamado de princípio da democracia.

Sendo assim, a escola ao atender, em sua essência, ao projeto societário maior, conduz um caminho discursivamente democrático de espaço de direito, ao passo que configura também em sua essência uma relação contraditória em sua própria gênese. Ou seja, constitui-se também como um espaço de reprodução social, de manutenção das relações de produção capitalista e de difusão da ideologia dominante. Ressalta Laval (2004, p. 190), "quaisquer que sejam a natureza e o teor de uma 'reforma' ou de uma 'inovação', é suficiente dizer que ela traduz uma modernização da escola para que, no espírito de muitos, ela seja sinônimo de progresso, de democracia, de adaptação à vida contemporânea etc". No entanto, por detrás das mudanças aparentemente "técnicas", a "modernização anuncia uma mutação da escola que toca não somente sua organização, mas seus valores e seus fins” (Laval, 2004, p. 189).

Diante da discussão que abarca a democratização do ensino, no final da década de 80 e início da década de 90, a temática da exclusão social e inclusão escolar ganham terreno nas discussões internacionais, e a inclusão escolar passa a ser vista como um novo modelo de atuação pedagógica a ser almejado e instituído pelas reformas educacionais de diversos países. Esses anseios passam a difundir-se principalmente a partir da realização de encontros internacionais na década de 90, como a Declaração Mundial sobre Educação para Todos em Jomtien, na Tailândia em 1990, e a Conferência Mundial sobre Necessidades Educacionais Especiais - NEE, Acesso e Qualidade em Salamanca, na Espanha em 1994.

No Brasil, desde a década de 90, o governo federal tem fomentado um conjunto de ações nas várias áreas dos serviços públicos como parte do que tem sido denominado de "políticas de inclusão 
social e escolar": o Bolsa-Família, o Programa de Erradicação do Trabalho Infantil e o Programa Educação Inclusiva são alguns exemplos desta política (Kassar, 2006). Foi a partir dessa década que a frequência de estudantes, que antes eram excluídos da escola regular, ganhou mais aparato governamental, uma vez que as crianças passam a ser amparadas pela Política Nacional de Educação Especial criada em 1994 e pela LDBEN de 1996. Em 2001, o Plano Nacional de Educação estabelecia objetivos e metas para a educação destes escolares. Em 2003 foi elaborado o Plano Decenal para Todos e a partir de 2004 o Programa Educação Inclusiva: Direito à diversidade, começou a ser introduzido nos municípios do país. Quanto ao Programa de Educação Inclusiva, de acordo com as Diretrizes Nacionais para Educação Especial na Educação Básica (Brasil, 2001), o Brasil fez opção pela construção de um sistema educacional inclusivo ao concordar e mostrar consonância com os postulados produzidos na Tailândia e em Salamanca. Dessa maneira, atualmente, a legislação brasileira posiciona-se pela permanência de todos os estudantes em salas regulares de ensino com o suporte do Atendimento Educacional Especializado - AEE. Atualmente, nota-se que os aparatos constitucionais em prol da educação inclusiva são bastante solidificados, mas será que esse conjunto de leis, decretos, portarias, assegura por si só a educação do estudante?

Os problemas que abarcam este tema não são tão simples de se resolver. Existe um descompasso entre o que se almeja e se propõe em lei, e a real viabilidade operacional das escolas públicas e privadas. De acordo com Fávero, Pantoja e Mantoan (2007), o que se vê na realidade como justificativa mais forte para a exclusão de crianças do ensino regular é a impossibilidade prática da inclusão. Veiga-Neto (2001, p. 109) já afirmava que apesar das políticas de inclusão terem sido impostas pelo governo, a inclusão acaba esbarrando na "resistência de muitos educadores conservadores", e de outro lado, enfrenta dificuldades de "ordem epistemológica ou mesmo prática", dificuldades que permanecem ainda nos dias de hoje. O despreparo dos profissionais da escola - diretor, coordenador pedagógico, equipe de limpeza e cozinha, auxiliares de sala e principalmente professores; a escassez e as defasagens de recursos pedagógicos e até mesmo físicos - materiais de apoio, estrutura física da escola, a rigidez curricular etc. - são algumas dessas dificuldades.

Com base nos elementos supracitados pensemos agora nos seguintes aspectos, o espaço e o tempo escolares. Cada um desses elementos constitui-se nas bases das condições materiais e/ou ideológicas na gênese da instituição escolar. Estes foram reconfigurados pelas novas demandas sócio-culturais na sociedade contemporânea (como a LDB), que, ao passo que delineou um novo comportamento acerca do tratamento dos direitos humanos e da acessibilidade, deflagrou a emergência de uma escola mais democrática, e de fato "acessível". Ora, nesse sentido, é inadiável considerarmos nesta discussão a escola como instituição democrática que deve realmente assegurar direitos fundamentais em igualdade de chances para todos que dela participam. Porém, observa-se que apesar do último século ser marcado pela intensidade de discursos que defendem a democracia e a igualdade de direitos, tais prerrogativas, todavia, não conseguiram suprir as necessidades impostas pela educação inclusiva.

Ao considerar a escola na atualidade, apesar das iniciativas e tentativas de mudanças, observa-se que a mesma ainda reproduz traços normativos, excludentes e que valorizam a escola de massas. A escola defende a democratização do ensino, mas, paradoxalmente, ao mesmo tempo retrata uma escola que buscou e busca a homogeneização de ritmos, processos, linguagens e saberes. 


\section{O ESPAÇO E O TEMPO NA RELAÇÃO PEDAGÓGICA}

Para a escola se constituir como um signo da civilização e do progresso, os intelectuais da época acreditavam que era necessário que a instituição escolar representasse um espaço organizado regido pela ordem e pela disciplina, "pela prescrição de uma nova economia do corpo e dos gestos, de formas racionais de empregar o tempo, ocupar o espaço e gerir o trabalho pedagógico" (Rocha, 2000, p. 2).

Ao considerarmos os postulados de dois séculos passados, observamos que a questão do tempo escolar entra em conflito com as concepções pedagógicas atuais que não conseguem se fazer presentes na lógica temporal vigente. Ora, um exemplo expresso dessa dificuldade é a lógica adotada atualmente, herdada do modelo instituído de escola, onde as aulas têm duração de 50 minutos com intuito de manter a disciplina e a ordem.

O modelo mnemônico de ensino que há tantos anos se fez presente nas salas de aula não encontra problemas e maiores dificuldades em realizar uma aula no espaço de tempo de 50 minutos. Para transcrever textos no quadro a fim de que os estudantes copiem a lição, para realizar ditados e atividades que priorizam a memorização da pluralidade de assuntos, como também, no caso específico da disciplina de geografia, para colorir mapas visando "conhecer" os espaços, esse tempo disponível era e é suficiente. Entretanto, ao se considerar a aprendizagem em ritmos diferentes, ou uma aprendizagem que busque por meio das experiências de vida dos estudantes estabelecer um raciocínio crítico da realidade, ou até mesmo uma aula de campo pelos arredores da escola, esse modelo de aula de 50 minutos é insuficiente e, até mesmo, inconcebível.

No intuito de conhecer e problematizar o espaço vivido do estudante, a questão do tempo escolar encontra um desafio ainda maior posto aos professores, não só os que trabalham com turmas com a presença de estudantes de inclusão, mas até mesmo uma sala de aula dita 'normal'. Em virtude das políticas educacionais vigentes no Brasil, os professores estão, em grande parte, atrelados a propostas educativas que exigem o cumprimento do currículo para, posteriormente, seus estudantes serem submetidos a avaliações normativas, o que acaba por "engessar" o professor e sua prática em sala de aula. O professor é levado, e muitas vezes condicionado, a trabalhar um conjunto de conteúdos em determinado espaço de tempo que leva a perpetuar no ensino o tão criticado ensino enciclopédico e mnemônico.

Além das dificuldades já apontadas no que diz respeito ao tempo, o espaço e a arquitetura escolar também necessitam se adequar para suprir as necessidades da escola inclusiva. A precariedade do espaço educacional no Brasil para receber estudantes de inclusão é fruto de políticas educativas desenvolvidas que, ao expandir o atendimento à população, não o fizeram acompanhado de corretas políticas de apoio. A acessibilidade das escolas públicas ainda é incipiente, muitas não possuem rampa de acesso, piso podotátil $1^{5}$, escadas e/ou banheiros adaptados.

Embora salientada a importância da estrutura física escolar adaptada aos padrões de acessibilidade, o espaço e a arquitetura da escola devem também ser encarados como um espaço educativo,

5 O piso podotátil é um piso diferenciado com textura e/ou cores salientes. Quando colocado com outros pisos, este piso se destaca com o objetivo de orientar a mobilidade de pessoas cegas e com baixa visão.

6 De acordo com Silva (1999, p. 78), "o currículo oculto é constituído por todos aqueles aspectos do ambiente escolar que, sem fazer parte do currículo oficial, explícito, contribuem, de forma implícita para aprendizagens sociais relevantes (...) o que se aprende no currículo oculto são fundamentalmente atitudes, comportamentos, valores e orientações". 
um espaço formativo que está presente no currículo oculto ${ }^{6}$ e que cumpre funções culturais e pedagógicas.

De acordo com Viñao Frago e Escolano (2001, p. 64), "o espaço jamais é neutro: em vez disso, ele carrega, em sua configuração como território e lugar, signos, símbolos e vestígios da condição e das relações sociais de e entre aqueles que o habitam". O espaço escolar diante da proposta da inclusão agrega em seus signos, símbolos e vestígios, outros elementos que são de suma importância na efetivação da proposta de escola inclusiva. Um exemplo do que está sendo discutido pôde ser vislumbrado nas escolas públicas do município de Florianópolis ${ }^{7}$ diante da inclusão de estudantes cegos e com baixa visão. Durante o ano letivo de 2009, 11 estudantes cegos estavam matriculados no ensino fundamental II e no ensino médio. Dentre as cinco escolas públicas da capital catarinense que atendiam estudantes cegos, somente duas passaram por grandes reformas há cerca de 17 anos e tentaram adaptar, um pouco, a sua estrutura física aos padrões de acessibilidade.

As duas escolas municipais que realizaram as reformas de seus espaços físicos contam com opções de rampa, escadas e banheiro adaptado. Contudo, a Escola Básica Municipal (E.B.M.) Batista Pereira não é sinalizada com piso podotátil, o que dificulta a movimentação do estudante cego matriculado há 4 anos na escola.

Diferente da E.B.M. Batista Pereira, a E.B.M. Donícia Maria da Costa sobressai aos olhos de quem a conhece, mais se parece a uma escola modelo - é toda sinalizada com piso podotátil e o teto de acrílico poupa o uso de energia elétrica. As salas de aula, a sala multimeios, a biblioteca e os banheiros estão distribuídos em dois pisos voltados para um único pavimento central, o que facilita a memorização e espacialização dos três estudantes cegos que ali estudaram em 2009.

Além das reestruturações de cunho físico realizadas nas duas escolas, ambas também receberam apoio didático-pedagógico quanto a materiais e a contratação e capacitação de professores. Nas escolas estão instaladas salas multimeios equipadas com computador, impressora, máquina Perkins Braillers (máquina de escrever em braille), alfabeto braille e materiais adaptados, e contam com o suporte de dois professores que realizam o Atendimento Educacional Especializado - AEE.

Para Viñao Frago (1995, p. 69), o "espaço diz e comunica". E para aqueles que conhecem a escola "Donícia", é perceptível na estrutura física a receptividade e abertura da escola para uma proposta de educação inclusiva. Os estudantes que frequentam a escola já estão familiarizados com os signos e os símbolos que apontam o seu caráter inclusivo.

O autor também apregoa que, para compreender a dimensão espacial da escola como atividade educativa, se deverá:

em primeiro lugar, considerar sua localização ou adequação em relação a outros espaços e lugares; depois, o local ou território ocupado e a distribuição, no mesmo, das zonas edificadas e não edificadas e, assim, seguir progressivamente, desde essas últimas até a sala de aula, passando pelo edifício em seu conjunto e sua distribuição interna em diversos espaços e usos (Viñao Frago; Escolano, 2001, p. 75).

7 CHAVES, Ana Paula Nunes. Ensino de Geografia e a cegueira: diagnóstico da inclusão escolar na Grande Florianópolis. Dissertação: CFH/UFSC, 2010. 
Outro ponto citado pelo autor e que também merece atenção é a "projeção espacial do estabelecimento de ensino e as relações com o seu entorno, isso é, sua área de captação e influência" (Viñao Frago; Escolano, 2001, p. 75).

Quando pensamos na projeção espacial da escola e, naturalmente, sua interferência e influência na comunidade onde está inserida, a escola "Donícia" traz uma característica peculiar diferente das demais escolas catarinenses que atendem estudantes cegos. A escola está localizada ao lado da Associação Catarinense para a Integração do Cego - ACIC, um centro de referência nacional e internacional no que concerne às atividades de reabilitação. Foi à procura deste auxilio que vários estudantes com cegueira e baixa visão mudaram-se para Florianópolis em busca de apoio, recursos e formação. As configurações espaciais fazem do bairro Monte Verde, onde está localizada a escola "Donícia" e a ACIC, um "bairro acessível". Vários estudantes que necessitam do auxílio da ACIC estudam e estudaram na escola e residem nos arredores das instituições. As calçadas das ruas são sinalizadas com piso podotátil, e tanto os funcionários da escola, como os moradores, conhecem sobre a cegueira e suas implicações. Por conta da interferência das instituições ali instaladas, e pela própria demanda gerada pelos novos moradores, houve uma reestruturação física e espacial do bairro visando a atender este público.

Tal constatação vai ao encontro das reflexões de Agostín Escolano quando aponta que "a ordenação do espaço, sua configuração como lugar, constitui um elemento significativo do currículo - independentemente de que aqueles que o habitam estejam, ou não, conscientes disso" (Viñao Frago; Escolano, 2001, p. 78). Nesse sentido, a localização da escola próxima à ACIC, o traçado arquitetônico do edifício escolar, seus elementos simbólicos próprios como as opções de acessibilidade na estrutura física e pedagógica, a sala multimeios onde é realizado o AEE, todos esses elementos "respondem a padrões culturais e pedagógicos que a criança internaliza e aprende" (Viñao Frago; Escolano, 2001, p. 45). E mais do que isso, segundo Gallego e Silva (2012, p. 5), "a dimensão do tempo, assim como a do espaço, não é uma propriedade natural dos indivíduos, mas sim uma ordem a ser aprendida".

\section{CONSIDERAÇÕES FINAIS}

Diante dos desafios impostos à escola, principalmente em prol da democratização e universalização do ensino, esse modelo cultural e social escolar necessita imperiosamente ser revisto e readequado às exigências atuais. Embora o modelo escolar vigente demonstre uma tendência de normalização, homogeneização e de mesmidade, a dinâmica instituída com as discussões sobre cultura escolar e escola inclusiva acaba por afetar essa lógica de pensamento determinista e excludente. A proposta de educação inclusiva gera na escola uma mudança significativa na estrutura de tempo e espaço estabelecida na medida em que considera o estudante como sujeito ativo do/no processo educativo, reconhecendo sua singularidade e as diferentes linguagens e ritmos de aprendizagem.

A atenção aos alunos diante da proposta de educação inclusiva passa necessariamente por considerar uma escola para todos, realmente democrática, na prática e na concretude do cotidiano. Segundo este pressuposto, entendemos que a escola é o espaço para a promoção da aprendizagem, e que para que esta forma de fazer escola, nesta forma de sociabilidade em que vivemos, se concretize de fato, precisaremos de uma resposta adequada às condições e caraterísticas dos estudantes. Ao ressaltar os diversos elementos que constituem e exemplificam a cultura escolar, dentre eles, principalmente, o tempo e o espaço escolares, percebe-se que a inclusão de todos os estudantes no ensino regular leva a uma alteração significativa de tais elementos. Assim, acreditamos que as mu- 
danças espaciais e estruturais na escola inclusiva não devem ser concebidas somente para atender as exigências da legislação. A escola precisa ser acessível para todos, e não somente para aqueles que necessitam de uma rampa ou um piso podotátil para entrar em sala de aula.

A inclusão escolar é uma inovação educacional e a escola precisa estar preparada para esta nova concepção de educação, a transformação e aprimoramento dessas escolas são inadiáveis, pois estes estudantes já fazem parte do contexto escolar, o que faz atualmente a inclusão acontecer por consequência.

Embora a escola regular seja o local preferencial para promoção da aprendizagem e inclusão de todos os estudantes, a presença de estudantes de inclusão nesse contexto não garante efetivamente que, mesmo com apoios e serviços especializados, não se configure uma situação de segregação física e/ou simbólica, ou até mesmo uma naturalização da exclusão. É importante a oferta de recursos e a existência de profissionais capacitados para atender as necessidades desses estudantes nas escolas, bem como uma discussão acerca da flexibilidade no currículo no intuito de garantir uma aprendizagem que priorize as potencialidades de cada um dos educandos e assegure a todos o direito de acesso ao conhecimento.

A chegada desses estudantes na escola tem levado a uma nova reestruturação do tempo e do espaço escolar. A adaptação dos espaços da sala de aula, do banheiro, do refeitório e de outros ambientes da escola, bem como a adequação no tempo destinado a realização de atividades, ao cumprimento do currículo escolar, a apresentação de trabalhos, precisam ser repensados uma vez que nem sempre o modelo instituído atualmente considera as particularidades de cada educando. É preciso privilegiar estudos sobre o tempo e o espaço escolares pois favorecem a discussão e aprimoramento da proposta de inclusão ao passo que ao considerar estes elementos nucleares da cultura escolar a escola se posiciona como um espaço aberto de reflexão e discussão democrática sobre as diferenças existentes nos estudantes, o repensar a escola a partir de um novo modelo de educação, uma educação que concebe a ipseidade de todos os atores envolvidos no processo educativo.

\section{BIBLIOGRAFÍA}

Bueno, J. G. S. (2008). As políticas de inclusão escolar: uma prerrogativa da educação especial? In: BUENO, J. G. S.; MENDES, G. M. L.; SANTOS, R. A. dos. Deficiência e escolarização: novas perspectivas de análise. Araraquara: Junqueira \& Marin; Brasília: CAPES. p. 43-66.

Chaves, A. P (2010). Ensino de Geografia e a cegueira: diagnóstico da inclusão escolar na Grande Florianópolis. Florianópolis, 2010. Dissertação (Mestrado em Geografia) - Departamento de Geociências, Universidade Federal de Santa Catarina.

Chervel, A. (1998). La culture scolaire: une approche historique. Paris: Belin.

De Paula, L. S. B. (2009). Cultura escolar, cultura surda e construção de identidades na escola. Revista Brasileira de Educação Especial, Marília, v.15, n.3, p.407-416, Set.-Dez.

Faria F. (2004). et al. A cultura escolar como categoria de análise e como campo de investigação na história da educação brasileira. Educação e Pesquisa, São Paulo, v. 30, n. 1, p. 139-159, jan./ abr. 
Forquin, J. (1993). Escola e cultura: as bases sociais e epistemológicas do conhecimento escolar. Porto Alegre: Artes Médicas.

Frigotto, G. (1993). A produtividade da escola improdutiva: um (re) exame das relações entre educação e estrutura econômico-social capitalista. 4.ed. São Paulo: Cortez.

Gallego, R. C.; Silva, V. B. (2010) A gestão do tempo e do espaço na escola. Material do Curso de Gestão da Escola para Diretores, realizado no Ambiente Virtual de Aprendizagem Rede de Formação Docente (REDEFOR/USP).

Habermas, J. (1997). Direito e democracia: entre facticidade e validade. Rio Janeiro: Tempo Brasileiro, v. 2.

Julia, D. (2001). A cultura escolar como objeto histórico. Revista Brasileira de História da Educação, Campinas, n. 1, p. 9-44.

Laval, C. (2004). A escola não é uma empresa: neo-liberalismo em ataque ao ensino público. Londrina: Editora Planta.

Rocha, H. H. P. (2000). Prescrevendo regras de bem viver: Cultura escolar e racionalidade científica. Cadernos Cedes, Campinas, ano XX, n. 52, p.1-19, Novembro.

Rodrigues, D. (2007). Educação Inclusiva: mais qualidade à educação. In: BRASIL. Ensaios pedagógicos - educação inclusiva: direito à diversidade. Brasília: Ministério da Educação, Secretaria de Educação Especial, p. 29-36.

Rosenfield, Denis L. O que é democracia. Coleção primeiros passos. São Paulo: Brasiliense, 2007.

Silva, T. T. (1999). Quem escondeu o currículo oculto. In: SILVA, T. T. da. Documento de identidade: uma introdução às teorias do currículo. Belo Horizonte: Autêntica, p. 77-152.

Veiga-Neto, A. (2001). Incluir para excluir. In: LARROSA, J; SLIAR, C. (org.). Habitantes de Babel: políticas e poéticas da diferença. Trad. Semíramis Gorini da Veiga. Belo Horizonte: Autêntica, p.105-118.

Viñao Frago, A. (1995). Historia de la educación e historia cultural. Revista Brasileira de Educação, São Paulo, n. 0, p. 63-82, set./dez.

Viñao Frago, A. (2006). Sistemas Educativos, Culturas Escolares y Reformas: Continuidades y Câmbios. Madrid: Morata.

Viñao Frago, A., Escolano, A. (2001). Currículo, espaço e subjetividade: a arquitetura como programa. Rio de Janeiro: DP\&A. 